\title{
ACO-BASED LOAD BALANCING SCHEME FOR MANETS
}

\section{Fatih Çelik}

Original scientific paper

Routing is one of the most important problems in Mobile Ad-hoc Networks (MANETs). Various techniques have been developed to cope with this problem. Ant-based routing is optimization technique used commonly. Ant-based routing is derived from ant colony optimization, which was inspired by ants. This article recommends a load balancing scheme based on the ant colony. The scheme recommended makes use of the on-demand path finding techniques. Using ant colony optimization develops these techniques. The scheme recommended reduced latency and packet loss without being affected by the increase in the scheme node number and the packet density. The comparisons are made via AODV and AntHocNet which are known as MANET routing algorithms.

Keywords: ACO; AntODV; load balancing; MANET

\section{ACO temeljena shema balansiranja opterećenja za MANETs}

Izvorni znanstveni članak

Usmjeravanje (routing) je jedan od najvažnijih problema u mobilnim ad-hoc mrežama (MANETs). Razvijene su različite tehnike za rješavanje tog problema. Usmjeravanje zasnovano na mravima (ant-based routing) je metoda optimizacije koja se općenito koristi. Nastala je iz optimizacije kolonije mrava, inspirirane mravima. Ovaj članak preporučuje shemu balansiranja opterećenja zasnovanu na koloniji mrava. Preporučena shema koristi tehniku pronalaženja putanje na zahtjev. Primjena optimizacije kolonije mrava razvija te tehnike. Preporučena shema smanjila je kašnjenje i gubitak paketa, a da na nju nije utjecalo povećanje broja čvorova i gustoće paketa u shemi. Napravljene su usporedbe putem AODV i AntHocNet poznatih kao MANET algoritmi usmjeravanja.

Ključne riječi: $A C O$; AntODV; balansiranje opterećenja; $M A N E T$

\section{Introduction}

Wireless devices have become widespread in recent years and are indispensable parts of our lives. Today, devices like television, mobile phones, and tablet and computers are able to communicate with each other wirelessly. With the increase of wireless devices, the control of data exchange between these devices has gained more importance.

Routing is one of the most important problems in Adhoc networks (MANETs) [1]. The fact that the nodes are mobile causes latency in the data flow and therefore, packet losses occur in routing. Thus, routing should be disorderly distributed between nodes and without central control with minimum data loss and latency without any external intervention. At the same time, the increase in the node number should affect routing at a minimum.

ACO is an algorithm based on the mathematical models of the behaviours of real ant colonies [2]. Antbased routing was proposed based on this algorithm. In ant-based routing, every node creates ants as their own control packets in order to find paths from the source to the target. These movements on the network vary according to the protocol developed. The ants' density and data packets change based on the pheromone power on the path. The paths on which pheromone is dense capture more ants [3].

Since the ants will use the shorter paths in the course of time, these paths will have more pheromone. Thus, the shortest path will be determined and all ants will use that path. Stagnation problem will arise as a result of the use of the same path by all ants and congestion will occur on the network. More than one path should be determined in MANETs because of the movement of all nodes. When the node is not tied in the most appropriate path, the other paths should be accessible. When topological changes take place new and better paths should be found [4].

Perkins and Royer, proposing a solution regarding the routing in MANETs, recommended the AODV protocol [5]. AODV is an on-demand routing protocol that establishes a path between the target and the source when the packet is available. For this routing, it used RREQ, RREP, and RRER messages [6]. Later on, many routing protocols inspired by AODV were recommended. Di Caro et al. recommended AntHocNet [7] routing protocol, which was inspired by Ant colony optimization. This protocol is a hybrid multipath scheme. Route information is not always stored on this protocol. Only when the need for a path rises, reactive forward ants are sent. These ants return to the source as backward ants by finding a multipath. Pheromone tables are formed and packets are routed to the paths stochastically according to the tables.

The purpose of this article is to develop a new load balancing scheme for Ad-hoc networks (MANETs) inspired by ant colonies. In our model, agents set off in order to discover all the paths. These paths are kept for a while for path repair. The paths kept are calculated stochastically by the formula developed by the source node and the packets are sent. At the same time, within this period, if a new packet is produced from these nodes, the node uses the most appropriate path without using a control packet. As each packet is sent, the same path is not used with the calculation made stochastically. Consequently, the traffic in the control packages system will not be blocked. Thus, measures are taken against the latency in packet delivery.

When organizing the article, the recommended methods will be presented in the second chapter. The performance comparisons of the methods recommended will be given in the third chapter. Recommendations 
regarding the results and the future studies will be presented in the fourth chapter.

\section{Background}

\subsection{Ant colony optimization (ACO)}

The ant colony optimization algorithm (ACO) is a probabilistic technique which can find good paths from source to destination.

This algorithm is a member of the ant colony algorithms, in swarm intelligence methods, and it constitutes some metaheuristic optimizations. Initially proposed by Marco Dorigo in 1992 [2], the first algorithm was aiming to search for an optimal path in a graph, based on the behaviour of ants seeking a path between their colony and a source of food.

In the natural world, ants wander randomly, and upon finding food return to their colony while laying down pheromone trails. If other ants find such a path, they are likely not to keep travelling at random, but to instead follow the trail, returning and reinforcing it if they eventually find food.

Over time, however, the pheromone trail starts to evaporate, thus reducing its attractive strength. The more time it takes for an ant to travel down the path and back again, the more time the pheromones have to evaporate. A short path, by comparison, gets marched over more frequently, and thus the pheromone density becomes higher on shorter paths than longer ones. Pheromone evaporation also has the advantage of avoiding the convergence to a locally optimal solution. If there were no evaporation at all, the paths chosen by the first ants would tend to be excessively attractive to the following ones. In that case, the exploration of the solution space would be constrained.

Thus, when one ant finds a good (short) path from the colony to a food source, other ants are more likely to follow that path, and positive feedback eventually leads to all the ants' following a single path. The idea of the ant colony algorithm is to mimic this behaviour with "simulated ants" walking around the graph representing the problem to solve [2].

\subsection{DEVS formalism}

DEVS-Suite [8] is modelling and simulation tool used in this study. This simulator tool is based on DEVS [11] approach. This approach has firstly been suggested in the book 'Theory of Modeling and Simulation' in 1976 by Dr. Bernard P. Zeigler for modelling and analysing of discrete event systems [9]. Because DEVS approach is discrete event based, modular and hierarchic, in recent times it is more appropriate for modelling and simulation than the other approaches $[10,11]$.

DEVS defines system behaviour in two different levels: Atomic and Coupled DEVS. Atomic DEVS defines autonomous behaviour of discrete event system that is as transitions between sequential situations, how it responds to the external input (events) and how it computes to the output (events) at the lowest level. Coupled DEVS defines a system as components network in higher level. Components can be atomic DEVS models and coupled DEVS models. Links show how they affect each other. A component's output event is able to the other component's input event due to the network. An atomic DEVS is possible to design for each coupled. Meanwhile, atomic or combined with A DEVS model that is atomic or coupled is possible to introduce as atomic DEVS model. Because coupled DEVS can have the other coupled DEVS, DEVS supports hierarchical structure modelling [12] .

DEVS approach advantages are stable connection between components, hierarchical design, event-based efficient simulation, object-oriented adaptation, low design time, advanced testing, better quality models, experimental environment facilitated, autonomous parallel / real-time operation, ease of verification and validation, interoperability, modelling using multiple methods and high performance [13]. In this study, performance achievements are proved by experiments by benefiting from the above advantages.

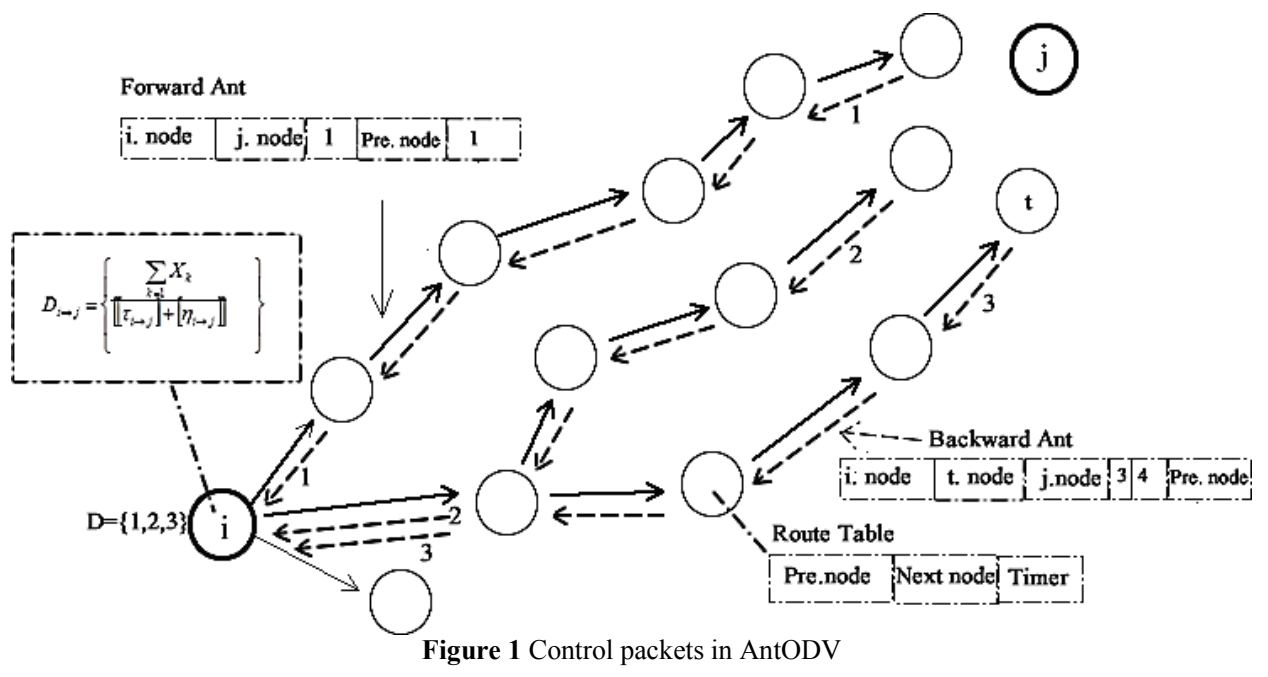

\section{Proposed scheme: AntODV}

In these pages, an ACO based load balancing scheme was performed. The scheme developed is a multi-hop scheme (Fig. 1). This scheme consists of four steps like other ACO based algorithms. The route setup step is performed on demand. Pheromone control is used for 
congestion. This control is based on the hop number. The

\subsection{Path finders}

The path is chosen based on these probabilities. It is highly probable that the paths with high pheromone density will be chosen.

In this study, during the path finding process, a data packet is made to move towards the target on demand on the forward ants network before data packet departs. Upon reaching the target, backward ants are created. When these ants go back to the source, the path information is formed.

When the source node sends a data packet for the first time, the forward ants have to be produced since there is no path information. The forward ants produced are spread on the network as broadcast. The forward ants spread on the network are:

- $\quad$ Source Address

- Destination Address

- Ant number

- Previous Address

- Cost.

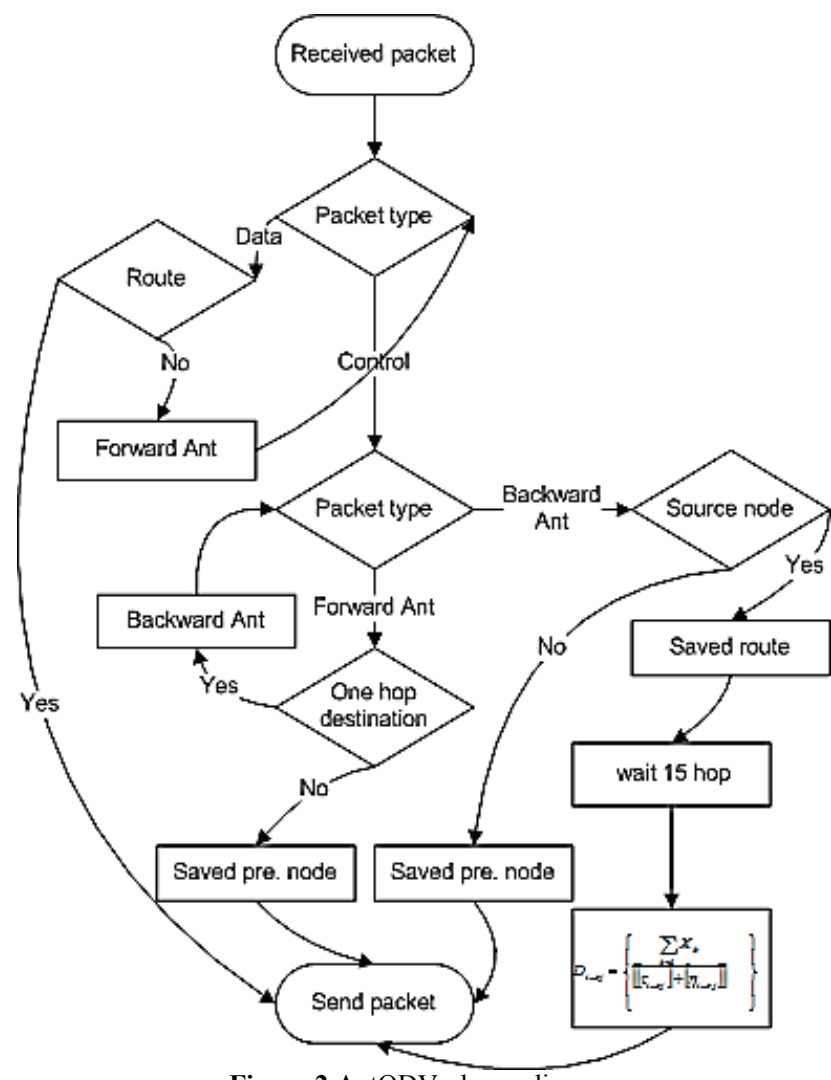

Figure 2 AntODVscheme diagram

Since the ant number nodes record the forward ants sent to the network, the same forward ants do not visit the same node. Forward ants reaching cost 15 are removed in order to prevent traffic increase on the network. The node records the number of forward ants passing on each node at the point where the ant comes for a certain time. Forward ants continue to proceed until a step is left for the target. When there is a step to the target, they transform themselves to backward ants.

When there is a skip distance left to the target node, the packets turned into backward ants set off again protocol developed embodies some features of AODV. towards the source node as unicast with the data they received from the forward ants. Backward ants carry:

- Source node

- Node at a heedful skip distance

- Target node

- Ant number

- Total cost

- Previous node Address.

Backward ants that will use different paths can be produced by the same node. While the backward ants go back to the source, they leave the node information where they came from on the node that they are passing. Thus, the information regarding the previous and the next node will be created on the node. Also, information about the ant that uses this path will be formed (Fig. 2).

\subsection{Data sending}

After the ants returning with path information reach the source node, path choosing is made from among these paths. The path choosing process is realized stochastically according to the paths' pheromone values as in the expression (1). In this way, the path-choosing probability is at the $D$ ratio. $X_{k}$, represents the total number of paths that an ant end could use to reach the $j$ target. $\tau$ represents the maximum pheromone; $\eta$ represents the minimum pheromone.

$D_{i \rightarrow j}=\left\{\begin{array}{c}\sum_{k=1} X_{k} \\ \left.\llbracket \tau_{i \rightarrow j}\right]+\left[\eta_{i \rightarrow j} \rrbracket\right.\end{array}\right\}$.

In $\mathrm{ACO}$, when the path choice is made, one of the paths on which it is possible to go, depending on a probability in proportion to the pheromone traces on the paths, is chosen. The path with the highest pheromone values is not always used.

\subsection{Path Maintenance}

Since the path-finding process is realized on demand, the information created by the source node and the nodes on the paths is stored for a short time. When a new data packet is formed again, the forward ants control the paths' pheromone values as unicast. In this control, the soundness and paths' pheromone values are examined. If the paths are solid, they are kept to be stored for a while on the source node and the nodes on the paths according to the pheromone value. If they are not, forward ants discover new paths. They get involved in the pheromones on other paths.

The paths on the network may break down in line with topology changes. Therefore, neighboring nodes send a Hello message to the nodes within their own scope at certain intervals in order to be informed about the presence of each other. Thus, they become aware of the presence of each other. Since the ants form the paths that they will use when necessary, there is no need to notify the paths that are broken down. 


\section{Simulation results \\ 4.1 Simulation frame}

The DEVS-Suite simulation device was used in AntODVscheme simulation. Parameters and values are shown in Tab. 1. Accordingly, simulation was performed in a $500 \times 500 \mathrm{~m}^{2}$ area for 300 seconds. The scope areas of the nodes were accepted as $250 \mathrm{~m}$. The node speeds were randomly chosen between $1 \div 10 \mathrm{~m} / \mathrm{s}$ during the simulation. The nodes were placed randomly by using the Waxman algorithm.

Table 1 Simulation parameters

\begin{tabular}{|l|c|}
\hline \multicolumn{1}{|c|}{ Parameter } & Value \\
\hline Topography & $500 \times 500 \mathrm{~m}^{2}$ \\
\hline Nodes & $60,70,80,90$ and 100 \\
\hline Mobility (m/s) & $1-10$ \\
\hline Topology generator & BRITE \\
\hline Packet Size (bytes) & 512 \\
\hline Simulation time (s) & i7, 4 GB RAM \\
\hline Computer & Ubuntu (64 bit) 10.04 LTS \\
\hline Operating system & WAXMAN \\
\hline Deployment algorithm & \\
\hline
\end{tabular}

\subsection{Performance analysis}

Two different comparisons were made via AODV and AntHocNet algorithms in order to make a performance evaluation of the AntODVscheme. In the first simulation, packet loss and average delay comparisons of the packets having 60, 70, 80, 90 and 100 nodes were made. In the second simulation, packet numbers were changed to $700,800,900,1000$ and similar comparisons were made.

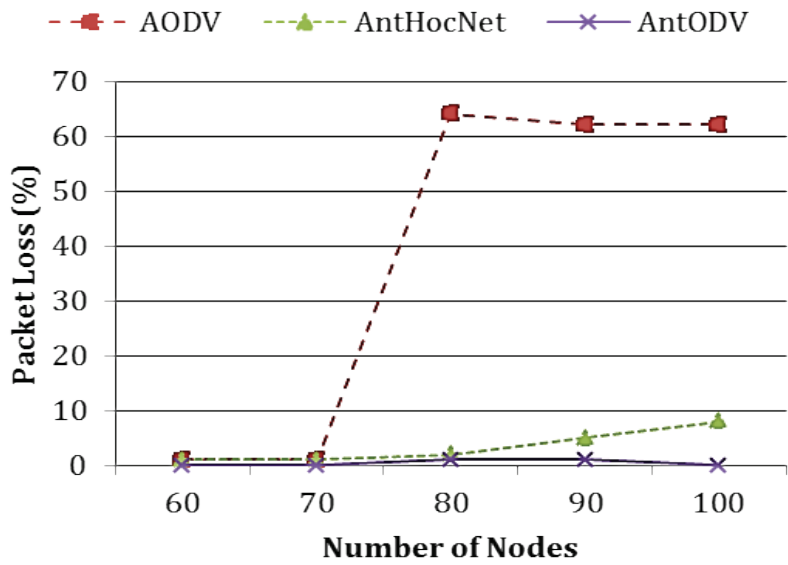

Figure 3 Packet loss ratio according to the number of nodes

We can see an important difference between our protocol and the AODV and AntHocNet protocols. As the protocol node number increased, the AODV protocol's packet loss increased (Fig. 2). AntHocNet tried to maintain its consistency as the node number increased but when 100 nodes was reached, the packet loss increased compared to the AntODV protocol. The reason is thatAntODV protocol stores the paths for a while and decreases the packet number. When packet density is examined, we have the same consistency in AntODV protocol. As the packet density increased AODV was not able to maintain its consistency and AntHocNet and Ant-
ODV were not affected by the traffic density (Fig. 4). The choice not to select the shortest path every time was the factor that caused latency in the AntODV. Nevertheless, AntODV is considered as the protocol that has the lowest latency ratio since the movement of a high number of packets is not allowed and path information is stored for a while (Figs. $3 \div 5$ ).

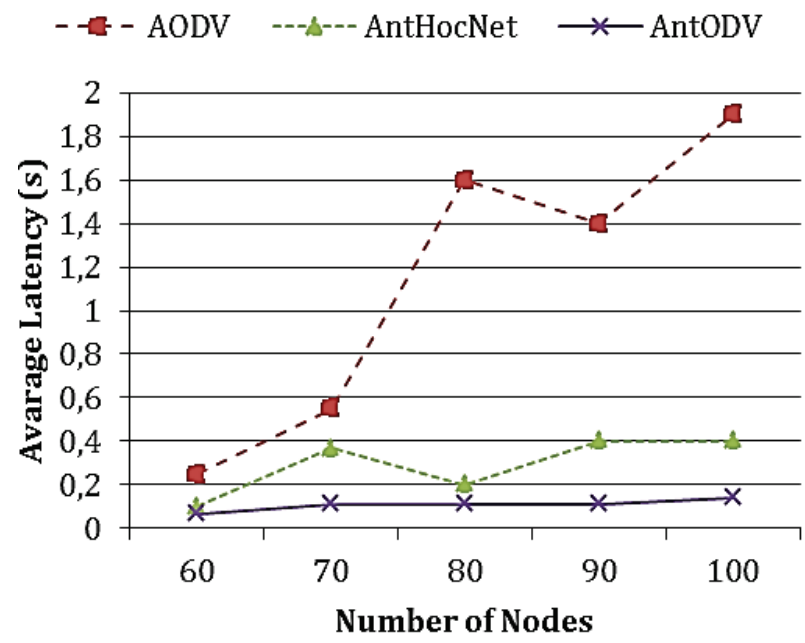

Figure 4 Latency (s) according to the number of nodes in the network

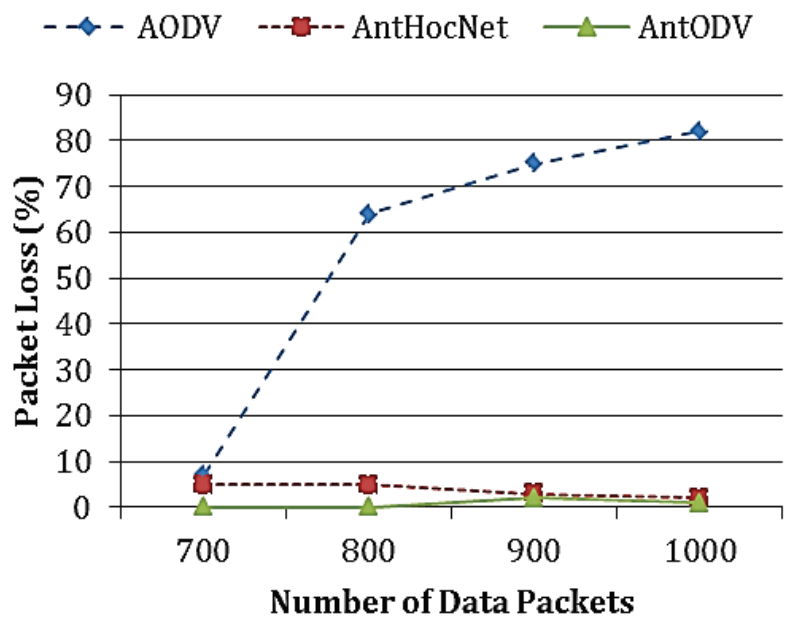

Figure 5 Packet loss ratio according to the total number of data packets

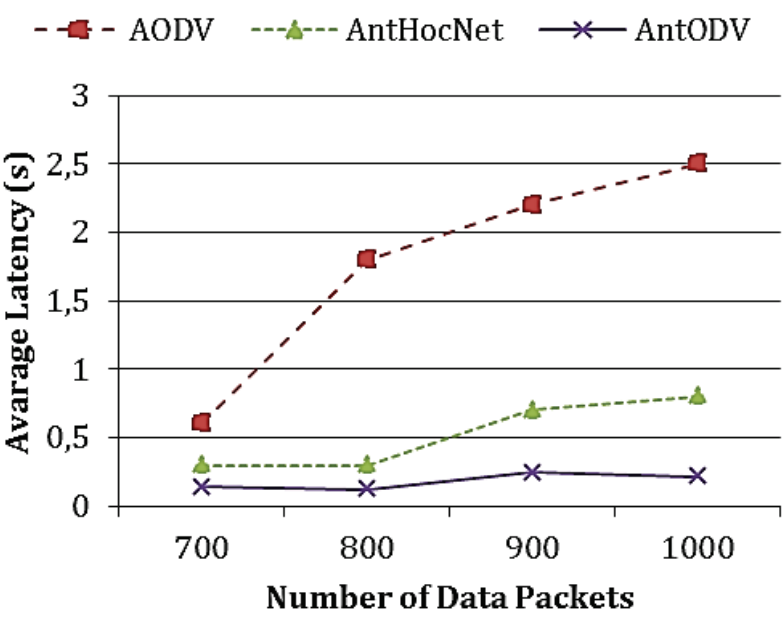

Figure 6 Latency (s) according to the total number of data packets 


\section{Conclusions}

In this paper, we proposed an ant-based load balancing scheme for MANET. We recommended AntODV because it reduces latency ratio and packet loss. It is seen that the algorithms recommended in the comparisons were able to fulfil what was desired. Despite the fact that traffic and node number increase in the MANET by using this scheme, the packets were delivered at $99 \%$ ratio in average. Additionally, as seen in the performance analysis, traffic and node number decreased in the latency compared to the other protocols. From both perspectives, it showed a superior performance to AODV and AntHocNet protocols.

\section{References}

[1] Shirkande, S. D.; Vatti, R. A. ACO Based Routing Algorithms for Ad-hoc Network (WSN, MANETs): A Survey. // $3^{\text {rd }}$ International Conference on Communication Systems and Network Technologies, 2013, pp. 230-235. DOI: 10.1109/csnt.2013.56

[2] Dorigo, M.; Maniezzo, V.; Colorni, A. Positive Feedback as a Search Strategy, N. 91-016 Politecnico di Milano, 1991.

[3] Abdel-Moniem, A. M.; Mohamed, M. H.; Hedar, A. An ant colony optimization algorithm for the mobile ad hoc network routing problem based on AODV protocol. // In IEEE $10^{\text {th }}$ International Conference on Intelligent Systems Design and Applications (ISDA 2010), 2010, pp. 13321337.

[4] Sim, K. M.; Sun, W. H. Ant Colony Optimization for Routing and Load-Balancing: Survey and New Directions. // IEEE Transaction on Systems, Man and Cybernetics. 33, 5(2003), pp. 560-572. DOI: 10.1109/TSMCA.2003.817391

[5] Perkins, C. E.; Royer, E. M. Ad hoc on-demand distance vector routing. // In Proceedings of the second IEEE workshop on mobile computing systems and applications, 1997, pp. 90-100.

[6] Shaik, S. B.; Setty, S. P. Performance Comparison of AODV, DSR and ANODR for Grid Placement Model. // International Journal of Computer Applications. 11, 12(2010), pp. 6-9. DOI: 10.5120/1637-2201

[7] Di Caro, G. A.; Ducatelle, F.; Gambardella, L. M. AntHocNet: an ant-based hybrid routing algorithm for mobile ad hoc networks. // In Proceedings of PPSNVIII, volume 3242 of LNCS, Springer, 2004, pp. 461-470. DOI: 10.1007/978-3-540-30217-9_47

[8] Kim, S.; Sarjoughian, H.; Elamvazhuthi, V. DEVS-Suite: A Simulator Supporting Visual Experimentation Design and Behavior Monitoring. // In Proceeding of the Spring Simulation Conferance, San Diego, CA, March 2009, pp. 29-36.

[9] Zeigler, B. P.; Praehofer, H.; Kim, T. G. Theory of modeling and simulation: integrating discrete event and continuous complex dynamic systems. Academic press, 2000.

[10] Zeigler, B. P.; Mittal, S. Modeling and Simulation of Ultra Large Networks: A Framework for New Research Directions. // In supported by NSF Grant ANI-0135530, ULN Workshop, (2002), pp. 1-34.

[11] Bourouis, A.; Belattar, B. Towards a metamodel for extended queuing networks. // International journal of Simulation Modelling. 11, (2012), pp. 221-224. DOI: 10.2507/IJSIMM11(3)1.190

[12] Zengin, A. Dağıtık Simülasyon Sistemleriiçin Yenibir Yönlendirme Algoritmasıve Uygulaması, Doktora Tezi, Sakarya Üniversitesi Fen Bilimleri Enstitüsü, 2004.
[13] Chow, A. Parallel DEVS: A Parallel, Hierarchical, Modular Modeling Formalism and Its Distributed Simulator. // International Transactions of the Society for Computer Simulation. 13, 2(1996), pp. 55-67.

\section{Author's address}

\section{Dr. Fatih Çelik}

Computer Engineering Department,

Technology Faculty, Sakarya University

Esentepe Campus Serdivan/Sakarya, Turkey

E-mail: fatihc@sakarya.edu.tr 